\title{
Effect of Decreased Skeletal Muscle Index and Hand Grip Strength on Functional Recovery in Subacute Ambulatory Stroke Patients
}

\author{
Jin Gee Park, MD ${ }^{1,2 *}$, Kyeong Woo Lee, MD ${ }^{1,2}$, Sang Beom Kim, MD ${ }^{1,2}$, \\ Jong Hwa Lee, $\mathrm{MD}^{1,2}$, Young Hwan Kim, $\mathrm{MD}^{1,2}$ \\ ${ }^{1}$ Department of Physical Medicine and Rehabilitation, Dong-A University College of Medicine, Busan; \\ ${ }^{2}$ Regional Cardiocerebrovascular Center, Dong-A Medical Center, Busan, Korea
}

Objective To investigate the effect of decreased Skeletal Muscle Index (SMI) and hand grip strength on functional recovery in subacute ambulatory stroke patients.

Methods Subacute stroke patients who were referred to the rehabilitation center were recruited. Decreased SMI and hand grip strength were diagnosed according to the Asian Working Group on Sarcopenia. Diagnostic criteria were decreased SMI and decreased unaffected hand grip strength. SMI was measured by bioelectrical impedance analysis. Unaffected hand grip strength was measured with a hand dynamometer. Patients were divided into two groups, decreased group (DG) and not-decreased group (NDG), according to the presence of decreased SMI and hand grip strength. Both groups received conventional stroke rehabilitation for 3 weeks. All patients were evaluated at the baseline and at 3 weeks after treatment. Functional status was evaluated with 4-meter walk test (4MWT), 6-minute walk test (6MWT), Timed Up and Go test (TUG), and Modified Barthel Index (MBI).

Results Both groups showed improvement in 4MWT, TUG, and MBI. NDG showed improvement in 6MWT. Comparing improvements between the two groups, NDG showed more improvement in 6MWT and TUG than DG. Conclusion The presence of decreased SMI and hand grip strength had negative effects on functional recovery in subacute ambulatory stroke patients.

Keywords Stroke, Subacute, Skeletal muscle index, Hand grip strength, Function

Received January 22, 2019; Accepted May 24, 2019

Corresponding author: Young Hwan Kim

Department of Physical Medicine and Rehabilitation, Dong-A Medical Center, Dong-A University College of Medicine, 26 Daesingongwon-ro, Seo-gu, Busan 49201, Korea. Tel: +82-51-240-5690, Fax: +82-51-254-8511, E-mail: dry815@hanmail.net

*Current affiliation: Department of Physical Medicine and Rehabilitation, Samsung Changwon Hospital, Sungkyunkwan University School of Medicine, Changwon, Korea

ORCID: Jin Gee Park (http://orcid.org/0000-0003-2672-1618); Kyeong Woo Lee (http://orcid.org/0000-0001-8785-5535); Sang Beom Kim (http:// orcid.org/0000-0002-5622-5933); Jong Hwa Lee (http://orcid.org/0000-0003-2489-358X); Young Hwan Kim (https://orcid.org/0000-0003-3249-5821).

(c) This is an open-access article distributed under the terms of the Creative Commons Attribution Non-Commercial License (http://creativecommons.org/ licenses/by-nc/4.0) which permits unrestricted noncommercial use, distribution, and reproduction in any medium, provided the original work is properly cited. Copyright @ 2019 by Korean Academy of Rehabilitation Medicine 


\section{INTRODUCTION}

Decreased Skeletal Muscle Index (SMI) and hand grip strength are major diagnostic components of sarcopenia. Characteristics of patients with decreased muscle mass and strength are expected to be similar to those of patients with sarcopenia. Sarcopenia was first introduced by Rosenberg in 1989 [1]. It was described as a general loss of muscle mass that occurred with advancing age. The definition of sarcopenia has evolved to account for body size, body fat, strength, and functions [2-5]. Some studies have reported that the loss of muscle mass and muscle function or the presence of sarcopenia is related to functional decline in the elderly $[6,7]$. Although the prevalence of sarcopenia has some variations due to different definitions, tools of diagnosis, and patient populations, the European Working Group on Sarcopenia in Older People (EWGSOP) has reported a prevalence of up to $29 \%$ in elderly community-dwelling populations and a prevalence of $14 \%-33 \%$ in long-term care populations [8]. Among various factors causing sarcopenia, advanced age has been consistently suggested as a major risk factor for sarcopenia [9-14].

Stroke is substantially prevalent among older patients. The risk of stroke rapidly rises with age, doubling each decade after age 55 [15]. As stroke and sarcopenia share the same risk factor which is age, they might have common comorbid state of diseases. In addition, these two diseases might influence each other's conditions. Nevertheless, there are few studies about the comorbidity of sarcopenia and stroke. Only several studies have reported the relationship between the two diseases about strokerelated sarcopenia $[16,17]$. These studies have reported that stroke-related sarcopenia has a number of features distinguishing from age-related sarcopenia, stating that sarcopenia is the chronic consequence of stroke. However, in patients with early stage of stroke, it is not reasonable to regard sarcopenia as a consequence of stroke. In addition, decreased muscle mass and strength might have influence on the recovery of stroke.

Since studies regarding the effect of sarcopenia or decreased muscle mass and strength in the early stage of stroke on recovery were lacking, the objective of this study was to investigate the effect of decreased SMI and hand grip strength on functional recovery in subacute ambulatory stroke patients.

\section{MATERIALS AND METHODS}

This study was approved by the Institutional Review Board of Dong-A University Hospital (No. DAUHIRB-19-052). Subacute stroke patients who were referred to rehabilitation center were recruited. Inclusion criterion was the first ever onset of stroke revealed by computed tomography or magnetic resonance images. To evaluate the effect of decreased SMI and hand grip strength on functional recovery in subacute phase of stroke, duration of stroke was limited to be from 1 week to 1 month. To prevent additional loss of muscle mass, patients started bedside rehabilitation with physical therapist in stroke care unit within 72 hours of admission. To accomplish functional evaluations, patient's status had to be at Functional Ambulation Category (FAC) 3 or 4 , indicating that they could walk under supervision or independently on even surface [18]. Patients with severe cognitive impairment having Mini Mental Status Examination (MMSE) score of less than 10, recurrent history of stroke, or other severely ill medical conditions that could have caused decline in muscle mass were excluded.

At admission, patients were evaluated for the presence of decreased SMI and hand grip strength. Diagnosis was made according to the definition agreed by the Asian Working Group for Sarcopenia (AWGS) [19]. For muscle mass measurement, SMI was calculated by Bioelectrical Impedance Analyses (InBody S10; InBody, Cerritos, CA, USA). Cutoff values were less than $7.0 \mathrm{~kg} / \mathrm{m}^{2}$ for men and $5.7 \mathrm{~kg} / \mathrm{m}^{2}$ for women. For muscle strength measurement, hand grip strength was measured with a hand dynamometer (EH101; Zhongshan Camry Electronic Co. Ltd., Zhongshan, China). Cutoff values were less than 26 $\mathrm{kg}$ for men and less than $18 \mathrm{~kg}$ for women. Most patients had hemiplegia due to stroke. Grip strength of the dominant hand could not be acquired in some patients. To substitute for dominant hand, unaffected side hand grip strength was measured. Patients were asked to sit in a straight-backed chair with their feet flat on the floor and elbow flexed to $90^{\circ}$. The arm was not supported and the dynamometer was held by the testing hand in a neutral grip. Patients were instructed to squeeze the handle as hard as possible for 3 seconds and the maximum contractile force $(\mathrm{kg})$ was recorded. Tests were performed three times with a 60 -second rest period between each trial. Mean value of the three repeated measurements 
was used for analysis. Although gait speed of less than $0.8 \mathrm{~m} / \mathrm{s}$ was in AWGS definition, all patients had gait problems due to stroke. Thus, gait speed had to be excluded in evaluation for sarcopenia. According to SMI and grip strength, patients were divided into two groups: decreased group (DG) and not-decreased group (NDG). Both groups received conventional rehabilitation treatments for 3 weeks. Treatments were consisted of stability training, gait training, and resistance training of hip and knee extensors. Stability and gait training were done 30 minutes per session, 2 sessions per day, 10 sessions per week for 3 weeks. Resistance training were done $30 \mathrm{~min}$ utes per session, 1 session per day, 5 sessions per week for 3 weeks.

All patients were evaluated at the baseline and at 3 weeks after treatment. Functional status was evaluated with 4-meter walk test (4MWT), 6-minute walk test (6MWT), Timed Up and Go test (TUG), and Modified Barthel Index (MBI). Ten categories of MBI were reorganized to three subcategories: activity of daily living (ADL), incontinence, and mobility. ADL consisted of personal hygiene, bathing, feeding, toileting, and dressing. Incontinence consisted of bowel and bladder control. Mobility consisted of stair-climbing, ambulation, and transfer.

All statistical analyses were conducted using SPSS ver- sion 20.0 for Windows (SPSS Inc., Chicago, IL, USA). Chi-squared test was used to compare sex, stroke type, stroke location, FAC, and dominant hand between the two groups. Mann-Whitney U-test was used to compare baseline characteristics and changes of measurements between the two groups. Wilcoxon signed rank test was used to determine changes between measurements in each group. A statistical significance level was set at $\mathrm{p}<0.05$.

\section{RESULTS}

During the study period, 146 stroke patients were admitted to our department. A total of 104 patients were excluded from this study. Thus, 42 were recruited (12 in DG and 30 in NDG). Three patients in NDG dropped out due to early discharge. Finally, 39 who completed all treatment sessions were investigated (Fig. 1). Baseline characteristics of these subjects are shown in Table 1. Twelve patients were in DG and 27 patients were in NDG. In DG, 6 were males and 6 were females. In NDG, 15 were males and 12 were females. In DG, 8 patients had infarction and 4 had hemorrhage. In NDG, 17 patients had infarction and 10 had hemorrhage. Mean age was $68.24 \pm 12.92$ years in DG and 64.85 \pm 9.73 years in NDG.

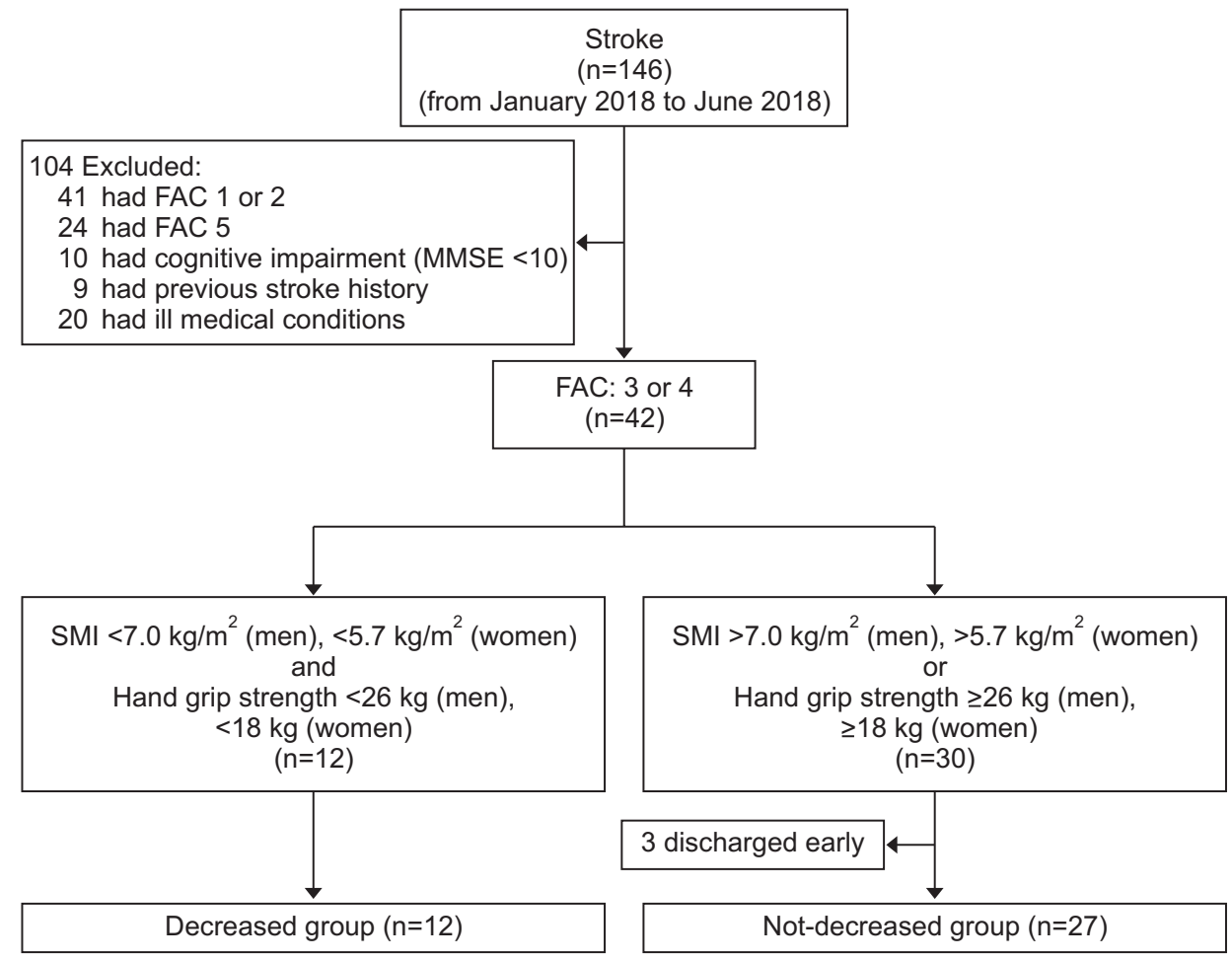

Fig. 1. Flowchart showing the enrollment of subjects. MMSE, MiniMental State Examination; FAC, Functional Ambulatory Category; SMI, Skeletal Muscle Index. 
Table 1. Baseline characteristics of patients enrolled in this study

\begin{tabular}{|c|c|c|c|}
\hline & DG & NDG & p-value \\
\hline Sex & & & 0.748 \\
\hline Male & 6 & 15 & \\
\hline Female & 6 & 12 & \\
\hline Stroke type & & & 0.824 \\
\hline Infarction & 8 & 17 & \\
\hline Hemorrhage & 4 & 10 & \\
\hline Age (yr) & $68.24 \pm 12.92$ & $64.85 \pm 9.73$ & 0.628 \\
\hline \multicolumn{4}{|l|}{ Stroke location } \\
\hline Left & 5 & 11 & 0.952 \\
\hline Right & 7 & 16 & \\
\hline Supratentorial & 11 & 22 & 0.820 \\
\hline Infratentorial & 1 & 5 & \\
\hline Initial NIHSS & $4.58 \pm 2.53$ & $3.85 \pm 4.52$ & 0.176 \\
\hline Initial mRS & $3.25 \pm 0.75$ & $3.28 \pm 0.61$ & 0.977 \\
\hline Stroke care unit stay (day) & $2.91 \pm 0.99$ & $2.78 \pm 1.18$ & 0.742 \\
\hline Stroke duration (day) & $14.17 \pm 5.42$ & $16.73 \pm 5.53$ & 0.617 \\
\hline FAC $(3 / 4)$ & & & 0.661 \\
\hline 3 & 8 & 16 & \\
\hline 4 & 4 & 11 & \\
\hline MMSE & $18.50 \pm 4.03$ & $18.85 \pm 3.92$ & 0.822 \\
\hline Penetration-Aspiration score & $4.25 \pm 2.70$ & $3.35 \pm 2.73$ & 0.297 \\
\hline Dominant hand & & & 0.781 \\
\hline Left & 0 & 1 & \\
\hline Right & 12 & 26 & \\
\hline \multicolumn{4}{|l|}{$\operatorname{SMI}\left(\mathrm{kg} / \mathrm{m}^{2}\right)$} \\
\hline Male & $6.55 \pm 0.41$ & $7.85 \pm 0.76$ & $0.041^{*}$ \\
\hline Female & $5.32 \pm 0.34$ & $6.25 \pm 0.40$ & $0.035^{*}$ \\
\hline \multicolumn{4}{|l|}{ Grip strength, unaffected (kg) } \\
\hline Male & $19.52 \pm 6.28$ & $34.63 \pm 5.61$ & $0.029 *$ \\
\hline Female & $12.52 \pm 3.67$ & $20.52 \pm 3.53$ & $0.032^{*}$ \\
\hline \multicolumn{4}{|l|}{ Function } \\
\hline $4 \mathrm{MWT}(\mathrm{m} / \mathrm{s})$ & $0.65 \pm 0.24$ & $0.78 \pm 0.32$ & 0.198 \\
\hline $6 \mathrm{MWT}(\mathrm{m})$ & $143.52 \pm 15.18$ & $155.64 \pm 17.85$ & 0.598 \\
\hline TUG (s) & $10.15 \pm 3.28$ & $9.84 \pm 3.67$ & 0.354 \\
\hline MBI & $73.13 \pm 9.66$ & $75.25 \pm 10.57$ & 0.698 \\
\hline ADL & $27.58 \pm 4.70$ & $30.44 \pm 3.30$ & 0.168 \\
\hline Incontinence & $14.83 \pm 6.63$ & $14.33 \pm 3.63$ & 0.776 \\
\hline Mobility & $30.92 \pm 2.19$ & $31.85 \pm 8.08$ & 0.391 \\
\hline
\end{tabular}

Values are presented as mean \pm standard deviation.

DG, decreased group; NDG, not-decreased group; NIHSS, National Institutes of Health Stroke Scale; FAC, Functional Ambulation Category; MMSE, Mini Mental Status Examination; SMI, Skeletal Muscle Index; 4MWT, 4-meter walk test; 6MWT, 6-minute walk test; TUG, Timed Up and Go test; MBI, Modified Barthel Index; ADL, activity of daily living. ${ }^{*} \mathrm{p}<0.05$ by Mann-Whitney U-test. 
Mean stroke duration from the onset of stroke to referral was 14.17 \pm 5.42 days in DG and 16.73 \pm 5.53 days in NDG. In DG, 5 had stroke in the left side and 7 had it in the right side. In NDG, 11 had stroke in the left side and 16 had it in the right side. In DG, 11 had stroke in supratentorial region and 1 had it in infratentorial region. In NDG, 22 had stroke in supratentorial region and 5 had it in infratentorial region. Mean initial National Institutes of Health Stroke Scale was 4.58 \pm 2.53 in DG and 3.85 \pm 4.52 in NDG. Mean modified Rankin Scale was 3.25 \pm 0.75 in DG and 3.28 \pm 0.61 in NDG. Mean duration of stay in stroke care unit was $2.91 \pm 0.99$ days in DG and $2.78 \pm 1.18$ days in NDG. Mean penetration-aspiration score following videofluoroscopic swallowing study was $4.25 \pm 2.70$ in DG and 3.35 \pm 2.73 in NDG. No patient in DG was left-handed while one patient in NDG was left-handed. In DG, 8 patients had FAC 3 and four patients had FAC 4. In NDG, 16 patients had FAC 3 and 11 had FAC 4. Mean MMSE was $18.50 \pm 4.03$ in DG and $18.85 \pm 3.92$ in NDG. Mean SMI of males was $6.55 \pm 0.41 \mathrm{~kg} / \mathrm{m}^{2}$ in DG and $7.85 \pm 0.76 \mathrm{~kg} / \mathrm{m}^{2}$ in NDG. Mean SMI of females was $5.32 \pm 0.34 \mathrm{~kg} / \mathrm{m}^{2}$ in DG and $6.25 \pm 0.40 \mathrm{~kg} / \mathrm{m}^{2}$ in NDG. Mean unaffected side grip strength of males was $19.52 \pm 6.28 \mathrm{~kg}$ in DG and 34.63 \pm 5.61 $\mathrm{kg}$ in NDG. Mean unaffected side grip strength of females was $12.52 \pm 3.67 \mathrm{~kg}$ in DG and 20.52 $\pm 3.53 \mathrm{~kg}$ in NDG. In functional evaluation, mean $4 \mathrm{MWT}$ was $0.65 \pm 0.24 \mathrm{~m} /$ $\mathrm{s}$ in DG and $0.78 \pm 0.32 \mathrm{~m} / \mathrm{s}$ in NDG. Mean $6 \mathrm{MWT}$ was $143.52 \pm 15.18 \mathrm{~m}$ in DG and $155.64 \pm 17.85 \mathrm{~m}$ in NDG. Mean TUG was $10.15 \pm 3.28$ seconds in DG and 9.84 \pm 3.67 seconds in NDG. Mean MBI was 73.13 \pm 9.66 in DG and
$75.25 \pm 10.57$ in NDG. Except for SMI or grip strength, other baseline characteristics showed no statistically significant difference between the two groups.

Changes of measurements at 3 weeks after treatment are shown in Table 2. In DG, 4MWT, TUG, and MBI were improved by $0.78 \pm 0.38 \mathrm{~m} / \mathrm{s}, 7.76 \pm 2.78$ seconds, $82.63 \pm 7.16$ and $3.67 \pm 0.51$, respectively. In NDG, 4MWT, 6MWT, TUG, and MBI were improved by $0.98 \pm 0.48 \mathrm{~m} /$ s, $202.18 \pm 20.71 \mathrm{~m}, 6.12 \pm 3.48$ seconds, $86.33 \pm 9.86$, and $3.67 \pm 0.48$, respectively. NDG showed additional improvement in 6MWT. Scores for three subcategories of MBI were increased in both groups after rehabilitation. In $\mathrm{DG}, \mathrm{ADL}$, incontinence, and mobility were improved by $32.58 \pm 1.50,16.67 \pm 3.44,33.25 \pm 3.25$, respectively. In NDG, ADL, incontinence, and mobility were improved by $33.67 \pm 3.51,16.81 \pm 3.19,35.19 \pm 2.54$, respectively.

Comparison results of changes in measurements between the two groups are shown in Table 3. In 6MWT, DG showed $28.87 \pm 7.71 \mathrm{~m}$ changes and NDG showed $47.52 \pm 9.55 \mathrm{~m}$ changes. In TUG, DG showed $-2.48 \pm 1.39$ second changes and NDG showed $-3.78 \pm 1.54$ second changes. NDG showed significantly more changes in 6MWT and TUG compared to DG.

\section{DISCUSSION}

This study found that decreased SMI and hand grip strength had negative effects on functional recovery in subacute ambulatory stroke patients. Patients without decrease of SMI or hand grip strength had additional im-

Table 2. Changes of measurements after treatment

\begin{tabular}{|lccccc}
\hline & \multicolumn{2}{c}{ DG } & & \multicolumn{2}{c}{ NDG } \\
\cline { 2 - 3 } \cline { 5 - 6 } & Baseline & After 3 weeks & & Baseline & After 3 weeks \\
\hline 4MWT $(\mathrm{m} / \mathrm{s})$ & $0.65 \pm 0.24$ & $0.78 \pm 0.38^{*}$ & & $0.78 \pm 0.32$ & $0.98 \pm 0.48^{*}$ \\
6MWT $(\mathrm{m})$ & $143.52 \pm 15.18$ & $172.52 \pm 21.18$ & & $155.64 \pm 17.85$ & $202.18 \pm 20.71^{*}$ \\
\hline TUG $(\mathrm{s})$ & $10.15 \pm 3.28$ & $7.76 \pm 2.78^{*}$ & & $9.84 \pm 3.67$ & $6.12 \pm 3.48^{*}$ \\
\hline MBI & $73.13 \pm 9.66$ & $82.63 \pm 7.16^{*}$ & & $75.25 \pm 10.57$ & $86.33 \pm 9.86^{*}$ \\
\hline ADL & $27.58 \pm 4.70$ & $32.58 \pm 1.50^{*}$ & & $30.44 \pm 3.30$ & $33.67 \pm 3.51^{*}$ \\
\hline Incontinence & $14.83 \pm 6.63$ & $16.67 \pm 3.44^{*}$ & & $14.33 \pm 3.63$ & $16.81 \pm 3.19^{*}$ \\
\hline Mobility & $30.92 \pm 2.19$ & $33.25 \pm 3.25^{*}$ & & $31.85 \pm 8.08$ & $35.19 \pm 2.54^{*}$ \\
\hline
\end{tabular}

Values are presented as mean \pm standard deviation.

DG, decreased group; NDG, not-decreased group; 4MWT, 4-meter walk test; 6MWT, 6-minute walk test; TUG, Timed Up and Go test; MBI, Modified Barthel Index; ADL, activity of daily living; FAC, Functional Ambulatory Category.

${ }^{*} \mathrm{p}<0.05$ by Wilcoxon signed-rank test. 
Table 3. Comparison of changes in measurements between the two groups

\begin{tabular}{lrrl}
\hline & \multicolumn{1}{c}{ DG } & \multicolumn{1}{c}{ NDG } & p-value \\
\hline$\Delta$ 4MWT $(\mathrm{m} / \mathrm{s})$ & $0.13 \pm 0.08$ & $0.20 \pm 0.12$ & 0.137 \\
$\Delta 6 \mathrm{MWT}(\mathrm{m})$ & $28.87 \pm 7.71$ & $47.52 \pm 9.55$ & $0.038^{*}$ \\
$\Delta$ TUG $(\mathrm{s})$ & $-2.48 \pm 1.39$ & $-3.78 \pm 1.54$ & $0.045^{*}$ \\
$\Delta$ MBI & $9.62 \pm 4.67$ & $11.08 \pm 7.96$ & 0.228 \\
\hline ADL & $3.21 \pm 4.47$ & $3.26 \pm 2.87$ & 0.774 \\
Incontinence & $3.33 \pm 3.44$ & $3.48 \pm 3.57$ & 0.877 \\
\hline Mobility & $2.33 \pm 3.96$ & $3.33 \pm 2.36$ & 0.284 \\
$\Delta$ FAC & $0.25 \pm 0.62$ & $0.26 \pm 0.44$ & 0.964 \\
\hline
\end{tabular}

Values are presented as mean \pm standard deviation.

DG, decreased group; NDG, not-decreased group; 4MWT, 4-meter walk test; 6MWT, 6-minute walk test; TUG, Timed Up and Go test; MBI, Modified Barthel Index; ADL, activity of daily living; FAC, Functional Ambulatory Category.

${ }^{*} \mathrm{p}<0.05$ by Mann-Whitney U-test.

provement in 6MWT. When comparing changes between the two groups, only patients without decreased SMI or hand grip strength showed improved changes in 6MWT and TUG.

Some studies have shown that decreased muscle mass and strength can influence function in several medical conditions. In community dwelling older adults, lower SMI was associated with cardiopulmonary functions [20]. In addition, there was a positive correlation between SMI and peak oxygen uptake [20]. Another study has reported that the elderly with sarcopenia is over three times more likely to fall than non-sarcopenic individuals regardless of age, gender, or other confounding factors [21]. Several studies have reported that the presence of sarcopenia in pre-operative state has negative outcomes. Harimoto et al. [22] have reported that patients with decreased muscle mass and strength in liver transplantation have worse liver function, greater blood loss, greater incidence of postoperative complications, and longer hospital stay. Similar results in colorectal cancer surgery and orthopedic surgery have also been reported [23,24]. In ankylosing spondylitis, SMI has positive correlation with spine mobility and strength [25]. In peripheral arterial disease, patients with decreased skeletal mass demonstrate decreased mobility and function [26]. In the case of stroke, age-related muscle atrophy has increased risk of dysphagia after stroke [27]. Another study has found that unaf- fected side grip strength is a predictive factor for shortterm functional gain and outcome after stroke [28]. The stronger the grip strength and the greater the difference between admission and discharge MBI, the greater the discharge MBI [28]. In accordance with other studies, our study found that decreased SMI and hand grip strength had negative influence on functional recovery of subacute ambulatory stroke patients. As decreased muscle mass and strength were proven to have negative effect on various medical conditions, they seemed to play the same role in stroke.

The present study evaluated functions mainly associated with gait. Although MBI represented overall function, other measurements including 4MWT, 6MWT, and TUG were also used in this study. For definition of sarcopenia, most studies evaluated gait speed as a representative of physical performance. The international working group on sarcopenia regarded gait speed of less than $1 \mathrm{~m} / \mathrm{s}$ as poor functional capacity [3]. The special interest group defined sarcopenia by gait speed of less than $0.8 \mathrm{~m} / \mathrm{s}$ using 4MWT [29]. The AWGS suggested gait speed of 0.8 $\mathrm{m} / \mathrm{s}$ as the cutoff value for low physical performance by walking $6 \mathrm{~m}$ at usual gait speed [19]. The foundation for the national institutes of health provided evidence that usual gait speed of less than $0.8 \mathrm{~m} / \mathrm{s}$ was associated with reduced survival and increased disability [30]. Because patients in the present study could not walk at usual speed due to hemiplegia, mean gait speed was less than $0.8 \mathrm{~m} / \mathrm{s}$ in both groups. Although hemiplegia had compromised gait speed, the absolute value of 4MWT after treatment in NDG showed improvement above the cutoff value of sarcopenia, implying that the presence of decreased SMI and hand grip strength had negative effects on stroke recovery. In addition to hemiplegia, decreased muscle mass and strength seemed to have led to decline in gait function. It might be associated with weakened plantar flexion and uncoordinated intersegmental lower limb motion that were observed in age-related sarcopenic elderly [31].

Besides changes of 4MWT, changes of 6MWT and TUG also showed improvement in NDG. 4MWT was used to evaluate gait speed only. 6MWT was used to evaluate gait endurance and TUG was used to evaluate overall functions such as balance and mobility. Although sarcopenia was defined as decreased physical performance by gait speed, there were other functional declines due to sar- 
copenia. Several studies have shown that sarcopenia has negative effects on balance [21], mobility [25,26], and overall function [28]. Loss of muscle mass and strength could be associated with not only gait speed, but also other functional parameters. Different changes in 6MWT and TUG between the two groups might be associated with decreased endurance and decline in balance and mobility.

There are some reports about association between gait and function. Usual gait speed is highly predictive for the onset of disability, severe mobility limitation, and mortality [32,33]. Poorer TUG is associated with poorer physical/mental function and mood status [34]. In geriatric population, gait speed is significantly slower in acute care settings compared to outpatient settings [35]. It has been shown that gait speed is an important measure in comprehensive geriatric assessment [35]. One study has reported that cutoff value of above $0.85 \mathrm{~m} / \mathrm{s}$ and $318 \mathrm{~m}$ could predict community walking after stroke [36]. According to that study, patients with similar stage as in our study could walk at speed of $0.72 \mathrm{~m} / \mathrm{s}$ [36]. Stroke patients with decreased SMI and hand grip strength in our study could walk at speed of $0.65 \mathrm{~m} / \mathrm{s}$. The reason for slower gait speed might be explained by the effect of decreased muscle mass and strength.

In the present study, patients with decreased SMI and hand grip strength showed lesser extent of recovery. To overcome the effect of these components of sarcopenia, some treatment options are available. Marty et al. [37] have reported that in elderly with sarcopenia, protein, vitamin D, creatine, and amino acid interventions in combination with resistance training can improve muscle mass, strength, and physical performance. Patients in DG of the present study received the same amount of resistance training as those in NDG. Tsekoura et al. [38] have reported that supervised strengthening exercise approach to sarcopenic population is effective for improving SMI, muscle mass, and gait speed. One report on congestive heart failure patients with low muscle mass has shown improvement by resistance training [39]. A recent metaanalysis has shown that low-intensity resistance training can sufficiently enhance the synthesis of muscle proteins, thus recommending it for maintaining skeletal muscle mass in frail older people [40]. It is well accepted that individuals performing resistance training are required to intake adequate protein. In addition, older adults may benefit from increased consumption of branched-chain amino acids [41]. Patients with decreased SMI and hand grip strength might need additional resistance exercise and nutritional support to diminish functional discrepancies.

This study has some limitations. First, this study evaluated the effect of decreased SMI and hand grip strength on stroke recovery only in subacute phase. Additional study in chronic phase may have different results. Second, this study mainly evaluated gait function. However, there could be other functional declines due to decreased muscle mass and hand grip strength such as dysphagia, cognition, spasticity, motor control, and so on. Third, sample size was relatively small. Lastly, even though we tried to minimize the effect of stroke on skeletal muscle and strength by shortening the immobilization period, other factors causing loss of muscle and strength such as denervation, endocrine dysfunction, and inflammatory process after the stroke could not be avoided. Further study might be needed to find out the comprehensive effects of decreased muscle mass and strength on stroke.

In conclusion, the present study found discrepancies in functional recovery between patients with decreases of SMI and hand grip strength and those without such decreases in subacute ambulatory stroke patients. The presence of decreased SMI and hand grip strength had negative effect on functional recovery in subacute ambulatory stroke patients. Thus, appropriate attention and supplementary treatment focusing on muscle mass and strength by strengthening exercise and nutritional support are needed when treating stroke patients with decreased SMI and hand grip strength.

\section{CONFLICT OF INTEREST}

No potential conflict of interest relevant to this article was reported.

\section{AUTHOR CONTRIBUTION}

Conceptualization: Park JK, Lee KW. Methodology: Lee KW, Kim SB, Lee JH. Formal analysis: Park JK, Kim YH. Writing - original draft: Park JK. Writing - review and editing: Kim YH. Approval of final manuscript: all authors. 


\section{REFERENCES}

1. Rosenberg IH. Summary comments: epidemiological and methodological problems in determining nutritional status of older persons. Am J Clin Nutr 1989;50:1231-33.

2. Cruz-Jentoft AJ, Baeyens JP, Bauer JM, Boirie Y, Cederholm T, Landi F, et al. Sarcopenia: European consensus on definition and diagnosis: Report of the European Working Group on Sarcopenia in Older People. Age Ageing 2010;39:412-23.

3. Fielding RA, Vellas B, Evans WJ, Bhasin S, Morley JE, Newman AB, et al. Sarcopenia: an undiagnosed condition in older adults. Current consensus definition: prevalence, etiology, and consequences. J Am Med Dir Assoc 2011;12:249-56.

4. Morley JE, Abbatecola AM, Argiles JM, Baracos V, Bauer J, Bhasin S, et al. Sarcopenia with limited mobility: an international consensus. J Am Med Dir Assoc 2011;12:403-9.

5. Cawthon PM, Peters KW, Shardell MD, McLean RR, Dam TT, Kenny AM, et al. Cutpoints for low appendicular lean mass that identify older adults with clinically significant weakness. J Gerontol A Biol Sci Med Sci 2014;69:567-75.

6. Dos Santos L, Cyrino ES, Antunes M, Santos DA, Sardinha LB. Sarcopenia and physical independence in older adults: the independent and synergic role of muscle mass and muscle function. J Cachexia Sarcopenia Muscle 2017;8:245-50.

7. Steffl M, Bohannon RW, Sontakova L, Tufano JJ, Shiells K, Holmerova I. Relationship between sarcopenia and physical activity in older people: a systematic review and meta-analysis. Clin Interv Aging 2017;12: 835-45.

8. Cruz-Jentoft AJ, Landi F, Schneider SM, Zuniga C, Arai $\mathrm{H}$, Boirie Y, et al. Prevalence of and interventions for sarcopenia in ageing adults: a systematic review. Report of the International Sarcopenia Initiative (EWGSOP and IWGS). Age Ageing 2014;43:748-59.

9. Han P, Kang L, Guo Q, Wang J, Zhang W, Shen S, et al. Prevalence and factors associated with sarcopenia in suburb-dwelling older Chinese using the Asian working group for sarcopenia definition. J Gerontol A Biol Sci Med Sci 2016;71:529-35.

10. Melton LJ 3rd, Khosla S, Crowson CS, O'Connor MK,
O'Fallon WM, Riggs BL. Epidemiology of sarcopenia. J Am Geriatr Soc 2000;48:625-30.

11. Tay L, Ding YY, Leung BP, Ismail NH, Yeo A, Yew S, et al. Sex-specific differences in risk factors for sarcopenia amongst community-dwelling older adults. Age (Dordr) 2015;37:121.

12. Figueiredo CP, Domiciano DS, Lopes JB, Caparbo VF, Scazufca M, Bonfa E, et al. Prevalence of sarcopenia and associated risk factors by two diagnostic criteria in community-dwelling older men: the São Paulo Ageing \& Health Study (SPAH). Osteoporos Int 2014;25: 589-96.

13. Bianchi L, Abete P, Bellelli G, Bo M, Cherubini A, Corica F, et al. Prevalence and clinical correlates of sarcopenia, identified according to the EWGSOP definition and diagnostic algorithm, in hospitalized older people: the GLISTEN study. J Gerontol A Biol Sci Med Sci 2017;72:1575-81.

14. Senior HE, Henwood TR, Beller EM, Mitchell GK, Keogh JW. Prevalence and risk factors of sarcopenia among adults living in nursing homes. Maturitas 2015; 82:418-23.

15. Ovbiagele B, Nguyen-Huynh MN. Stroke epidemiology: advancing our understanding of disease mechanism and therapy. Neurotherapeutics 2011;8:319-29.

16. Scherbakov N, Sandek A, Doehner W. Stroke-related sarcopenia: specific characteristics. J Am Med Dir Assoc 2015;16:272-6.

17. Hunnicutt JL, Gregory CM. Skeletal muscle changes following stroke: a systematic review and comparison to healthy individuals. Top Stroke Rehabil 2017;24: 463-71.

18. Mehrholz J, Wagner K, Rutte K, Meissner D, Pohl M. Predictive validity and responsiveness of the functional ambulation category in hemiparetic patients after stroke. Arch Phys Med Rehabil 2007;88:1314-9.

19. Chen LK, Liu LK, Woo J, Assantachai P, Auyeung TW, Bahyah KS, et al. Sarcopenia in Asia: consensus report of the Asian working group for sarcopenia. J Am Med Dir Assoc 2014;15:95-101.

20. Sugie M, Harada K, Takahashi T, Nara M, Ishikawa J, Koyama T, et al. Relationship between skeletal muscle mass and cardiac function during exercise in community-dwelling older adults. ESC Heart Fail 2017;4:40916.

21. Landi F, Liperoti R, Russo A, Giovannini S, Tosato M, 
Capoluongo E, et al. Sarcopenia as a risk factor for falls in elderly individuals: results from the ilSIRENTE study. Clin Nutr 2012;31:652-8.

22. Harimoto N, Yoshizumi T, Izumi T, Motomura T, Harada $\mathrm{N}$, Itoh $\mathrm{S}$, et al. Clinical outcomes of living liver transplantation according to the presence of sarcopenia as defined by skeletal muscle mass, hand grip, and gait speed. Transplant Proc 2017;49:2144-52.

23. Chen WZ, Chen XD, Ma LL, Zhang FM, Lin J, Zhuang $\mathrm{CL}$, et al. Impact of visceral obesity and sarcopenia on short-term outcomes after colorectal cancer surgery. Dig Dis Sci 2018;63:1620-30.

24. Bokshan SL, DePasse JM, Daniels AH. Sarcopenia in orthopedic surgery. Orthopedics 2016;39:e295-300.

25. Kim SC, Lee YG, Park SB, Kim TH, Lee KH. Muscle Mass, Strength, mobility, quality of life, and disease severity in ankylosing spondylitis patients: a preliminary study. Ann Rehabil Med 2017;41:990-7.

26. Addison O, Prior SJ, Kundi R, Serra MC, Katzel LI, Gardner AW, et al. Sarcopenia in peripheral arterial disease: prevalence and effect on functional status. Arch Phys Med Rehabil 2018;99:623-8.

27. Sporns PB, Muhle P, Hanning U, Suntrup-Krueger S, Schwindt W, Eversmann J, et al. Atrophy of swallowing muscles is associated with severity of dysphagia and age in patients with acute stroke. J Am Med Dir Assoc 2017;18:635.

28. Yi Y, Shim JS, Oh BM, Seo HG. Grip strength on the unaffected side as an independent predictor of functional improvement after stroke. Am J Phys Med Rehabil 2017;96:616-20.

29. Muscaritoli M, Anker SD, Argiles J, Aversa Z, Bauer JM, Biolo G, et al. Consensus definition of sarcopenia, cachexia and pre-cachexia: joint document elaborated by Special Interest Groups (SIG) "cachexia-anorexia in chronic wasting diseases" and "nutrition in geriatrics". Clin Nutr 2010;29:154-9.

30. Studenski SA, Peters KW, Alley DE, Cawthon PM, McLean RR, Harris TB, et al. The FNIH sarcopenia project: rationale, study description, conference recommendations, and final estimates. J Gerontol A Biol Sci Med Sci 2014;69:547-58.

31. Ogaya S, Iwata A, Higuchi Y, Fuchioka S. The association between intersegmental coordination in the low- er limb and gait speed in elderly females. Gait Posture 2016;48:1-5.

32. Guralnik JM, Ferrucci L, Pieper CF, Leveille SG, Markides KS, Ostir GV, et al. Lower extremity function and subsequent disability: consistency across studies, predictive models, and value of gait speed alone compared with the short physical performance battery. J Gerontol A Biol Sci Med Sci 2000;55:M221-31.

33. Cesari M, Kritchevsky SB, Newman AB, Simonsick EM, Harris TB, Penninx BW, et al. Added value of physical performance measures in predicting adverse health-related events: results from the Health, Aging And Body Composition Study. J Am Geriatr Soc 2009; 57:251-9.

34. Liu LK, Chen LY, Peng LN, Liu CL, Lin MH, Chen LK. Timed up-and-go test: a potential indicator for successful aging of older men in Taiwan. J Aging Res Clin Practice 2013;2:152-6.

35. Peel NM, Kuys SS, Klein K. Gait speed as a measure in geriatric assessment in clinical settings: a systematic review. J Gerontol A Biol Sci Med Sci 2013;68:39-46.

36. An S, Lee Y, Shin H, Lee G. Gait velocity and walking distance to predict community walking after stroke. Nurs Health Sci 2015;17:533-8.

37. Marty E, Liu Y, Samuel A, Or O, Lane J. A review of sarcopenia: Enhancing awareness of an increasingly prevalent disease. Bone 2017;105:276-86.

38. Tsekoura M, Billis E, Tsepis E, Dimitriadis Z, Matzaroglou $\mathrm{C}$, Tyllianakis $\mathrm{M}$, et al. The effects of group and home-based exercise programs in elderly with sarcopenia: a randomized controlled trial. J Clin Med 2018; 7:E480.

39. Yamada S, Kamiya K, Kono Y. Frailty may be a risk marker for adverse outcome in patients with congestive heart failure. ESC Heart Fail 2015;2:168-70.

40. Schoenfeld BJ, Grgic J, Ogborn D, Krieger JW. Strength and hypertrophy adaptations between low- vs. highload resistance training: a systematic review and meta-analysis. J Strength Cond Res 2017;31:3508-23.

41. Yoshimura Y, Uchida K, Jeong S, Yamaga M. Effects of nutritional supplements on muscle mass and activities of daily living in elderly rehabilitation patients with decreased muscle mass: a randomized controlled trial. J Nutr Health Aging 2016;20:185-91. 